\title{
Digital Nerve Sensory Potentials in Lesions of Cervical Roots and Brachial Plexus
}

\author{
Michael Newman and Norma Nelson
}

\begin{abstract}
SUMMARY: Normal values for the amplitudes of digital sensory nerve action potentials were obtained from 190 control subjects, using an orthodromic surface-recording technique. Lower limits were calculated, taking into account laterality, age and sex; the ratios of amplitudes between different digits were also estimated. The results in control subjects were compared with those of 20 cases of trauma involving root avulsion or extraspinal injury, 38 patients with intraspinal disease, 6 patients with extraspinal disorder and 9 cases of neuralgic amyotrophy. The variability of the dermatomes is discussed and it is concluded that digital sensory potential amplitudes offer a useful method of determining the site of a nerve lesion, provided certain limitations are recognized.
\end{abstract}

RÉSUMÉ: Les valeurs normales de l'amplitude des potentiels d'action sensitifs digitaux ont été obtenues chez 190 sujets contrôles, à l'aide d'une technique orthodromique avec enregistrement de surface. On a calculé les valeurs limites inférieures en référence au côté, à l'âge et au sexe des sujets. Les rapports d'amplitude entre les différents doigts ont aussi été mesurés. Les résultats du groupe contrôle ont été comparés à ceux de 20 patients souffrant d'avulsion de racines ou de traumatisme extrarachidien, 38 patients avec atteinte intraspinale, 6 malades avec une pathologie extramédullaire et 9 cas d'amyotrophie douloureuse. La variabilité des dermatomes est discutée et on conclut que l'amplitude des potentiels sensitifs digitaux offre une méthode utile pour la détermination du niveau d'atteinte nerveuse périphérique pourvu que certaines limites soient reconnues.

Can. J. Neurol. Sci. 1983; 10:252-255

Disorders of the cervical nerve roots and of the brachial plexus are often difficult to diagnose by clinical means. Distinction between lesions inside and outside the spinal canal may make an important difference to treatment and prognosis.

Electrophysiological investigation of proximal nerve lesions has included a variety of methods. Bonney and Gilliatt (1958) used sensory nerve action potentials (SNAPs) from digital nerves as an indicator of whether a lesion was proximal or distal to the dorsal root ganglion. The present investigation was undertaken to determine whether quantitative analysis of amplitude can give more information than simple presence or absence of sensory potentials.

\section{MethodS}

Digital nerve potentials were recorded orthodromically using the technique described by Cruz-Martinez et al., (1978a). Each digit was stimulated through ring or clip electrodes with a stimulus duration of $0.1 \mathrm{msec}$ and sufficient current to give a maximum response. The fingers were electrically isolated from each other with paper. Potentials were recorded with two gold cup electrodes, $8 \mathrm{~mm}$ in diameter, fixed with their centres $3 \mathrm{~cm}$ apart in a plastic holder; the electrodes were positioned over the median or ulnar nerve at the wrist. The temperature of the palm was at or above $30^{\circ} \mathrm{C}$. The responses were amplified with a bandpass of $10 \mathrm{~Hz}-2 \mathrm{KHz}$. Amplitudes were measured peak to peak from an average of 4-16 responses.

\section{Control Subjects}

The 190 control subjects included a group of 51 persons who were hospital staff or relatives and were aged 22 to 68 years; the remainder were 139 patients, aged 23 to 73 , referred to the EMG Department but who had a final diagnosis other than neurological disease. No subject was included who had any evidence of peripheral nerve disorder.

\section{Results}

\section{Control Subjects}

The mean amplitudes of the responses for corresponding digits were found to be greater in females and slightly higher in left hands than right, as noted by Cruz-Martinez et al. (1978b). There was considerable diminution of amplitude with age. The amplitudes did not follow a normal distribution, but were positively skewed with kurtosis. The variability was such that twice the standard deviation below the mean produced a value less than zero. Estimates were therefore made of $5 \%$ and $10 \%$ cutoff points such that, with $95 \%$ probability, no more than the stated percentage of the population would have values below these limits. This value was termed the " $5 \%$ " or " $10 \%$ " lower limit (Tables 1 and 2). Calculation of a ratio of amplitudes on different digits may be used in some circumstances to overcome the effects of variability in sex, side and age (Table 3). The ratio of digit five to other digits was more variable than other ratios.

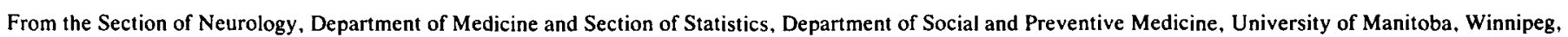
Manitoba.

Received September 30, 1982. Accepted in revised form August 16, 1983.

Requests for reprints to: Dr. M. Newman, EEG/EMG Department, Health Science Centre, 700 William Avenue, Winnipeg, Manitoba R2E 0Z3. 
Table 1: Normal values for amplitude of median nerve sensory action potential on stimulation of digit 3

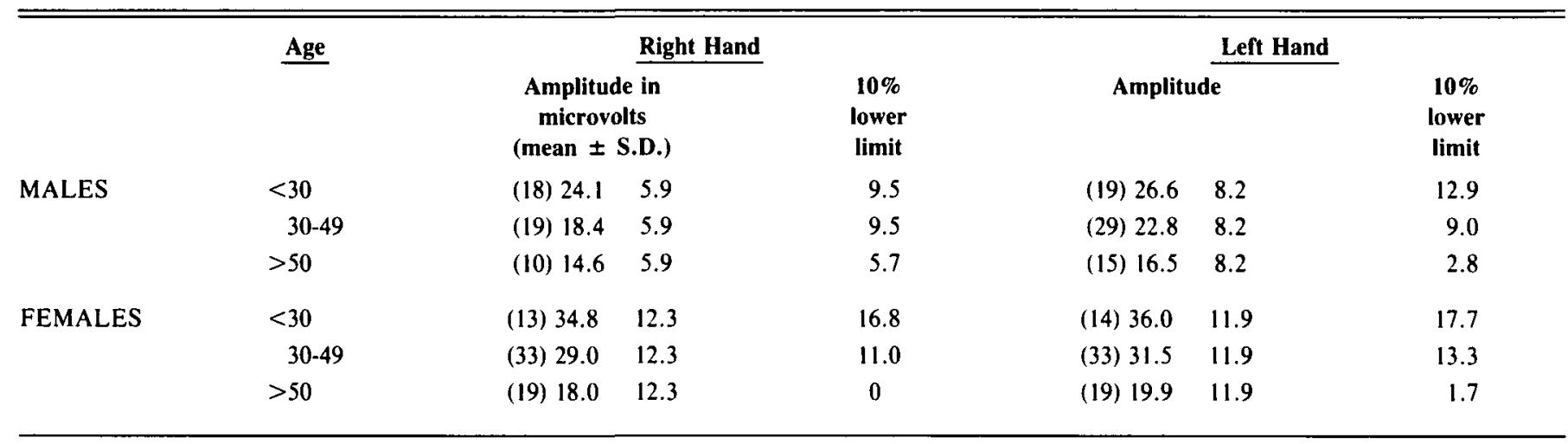

Figures in brackets indicate number of subjects tested in each group.

Table 2: Normal values for amplitude for ulnar nerve sensory action potential on stimulation of digit 5

\begin{tabular}{|c|c|c|c|c|c|c|c|}
\hline & Age & $\begin{array}{c}\text { Amplitude in } \\
\text { microvolts } \\
\text { (mean } \pm \text { S.D.) }\end{array}$ & $\begin{array}{c}10 \% \\
\text { lower } \\
\text { limit }\end{array}$ & $\begin{array}{c}5 \% \\
\text { lower } \\
\text { limit }\end{array}$ & Amplitude & $\begin{array}{l}10 \% \\
\text { lower } \\
\text { limit }\end{array}$ & $\begin{array}{l}5 \% \\
\text { lower } \\
\text { limit }\end{array}$ \\
\hline MALES & $\begin{aligned}< & 30 \\
& 30-49 \\
> & 50\end{aligned}$ & $\begin{array}{l}\text { (18) } 16.6 \pm 5.8 \\
\text { (19) } 11.4 \pm 5.8 \\
\text { (10) } 6.9 \pm 5.8\end{array}$ & $\begin{array}{r}10.1 \\
4.9 \\
0.4\end{array}$ & $\begin{array}{l}8.3 \\
3.2 \\
0\end{array}$ & $\begin{array}{l}\text { (19) } 17.2 \pm 5.6 \\
(29) 12.1 \pm 5.6 \\
\text { (15) } 6.2 \pm 5.6\end{array}$ & $\begin{array}{l}9.1 \\
4.0 \\
0\end{array}$ & $\begin{array}{l}6.3 \\
1.2 \\
0\end{array}$ \\
\hline
\end{tabular}

Figures in brackets indicate number of subjects tested in each group.

Table 3: Ratios of sensory potential amplitudes on digits for central subjects

\begin{tabular}{llcccc}
\hline \hline & Ratio \pm S.D. & $\begin{array}{c}\mathbf{5 \%} \\
\text { upper } \\
\text { limit }\end{array}$ & $\begin{array}{c}\mathbf{1 0 \%} \\
\text { upper } \\
\text { limit }\end{array}$ & $\begin{array}{c}\mathbf{5 \%} \\
\text { lower } \\
\text { limit }\end{array}$ & $\begin{array}{c}\mathbf{1 0 \%} \\
\text { lower } \\
\text { limit }\end{array}$ \\
\hline Digit 1:3 & $1.1 \pm 0.36$ & & & & \\
Digit 2:3 & $0.85 \pm 0.25$ & 2.0 & 1.8 & 0.5 & 0.6 \\
Digit 5:3 & $0.6 \pm 0.28$ & 1.5 & 1.3 & 0.5 & 0.5 \\
Digit 3 (R:L) & $0.95 \pm 0.27$ & & 1.2 & & $(190)$ \\
& & & 1.7 & & $(190)$ \\
\hline
\end{tabular}

The actual percentages vary slightly from $10 \%$ due to the discrete nature of the measurements. Figures in brackets indicate number of subjects tested in each group.

\section{Traumatic Lesions of Cervical Roots and Brachial Plexus}

Six patients aged 19 to 29 had clinical findings suggestive of root avulsion of upper roots in four (C5,6 in two, C5,6 and 7 in two) of all roots except $\mathrm{CS}$ in one and of all roots in one other patient. The serratus anterior showed denervation in all six patients; the paraspinal muscles in only one. SNAP amplitudes, measured one to six months after injury, were abnormally low for one or more digits in every case but other digits with clinical sensory loss had SNAP amplitudes within the normal range. The low amplitude SNAPs may have been due to concurrent trauma distal to the dorsal root ganglia and did not seem related to the time elapsed since injury. Even after five years, one patient had a measurable SNAP on a completely anesthetic digit.

Eleven patients, newborn to age 16 , had histories of injury to the supraclavicular or axillary regions. The upper part of the plexus was involved in five, the lower part in seven. SNAP amplitudes were below the $10 \%$ limit on digits with clinical sensory loss in all cases and below the $5 \%$ lower limit in all but two. In three patients who had sensory loss in only one digit, SNAPs were abnormally small in several digits. One patient suffered a penetrating injury which completely severed the C5 
and 66 roots in the posterior triangle of the neck. A small SNAP was still present on stimulation of the thumb. Evidently this digit was partly innervated by $\mathrm{C} 7$. Three patients had no definite involvement of serratus anterior or of paraspinal muscles, but the presence of normal SNAPs on digits with sensory loss suggested an avulsion injury. This was not inconsistent with the apparent mechanism of trauma, but could not be confirmed.

\section{Cervical Spondylosis and Disc Lesions}

Conditions which characteristically affect cervical roots proximal to the dorsal root ganglia include cervical spondylosis and the less common cervical disc protrusion. Twenty-nine patients were diagnosed as having root compression due to spondylosis on the basis of pain and clinical signs and the finding of a narrow foramen on oblique $x$-rays. Seven were diagnosed as disc protrusion on the basis of similar signs and myelography. One patient was found to have spinal stenosis from $\mathrm{C5}$ to $\mathrm{C} 7$ and one had neurofibroma arising from the $\mathrm{C} 6$ root. When $x$-ray abnormalities were present at multiple levels, a depressed triceps jerk and denervation of the triceps were assumed to indicate $\mathrm{C} 7$ involvement; depressed biceps jerk to indicate $\mathrm{C} 6$. It is realized that these myotomes are probably variable.

One patient with what was assumed to be $C 7$ root compression due to spondylosis had absent SNAPs from the first three digits but normal potentials from the fifth. Three others had high digit five to three amplitude ratios. All the other amplitudes and ratios were in the range which might be expected in a normal population at this age; most of this group were over 50 years. The findings were similar to those of Benecke and Conrad (1980).

\section{Extraspinal Lesion}

A man aged 57 and two women aged 22 and 23 with clinical signs of thoracic outlet syndrome were referred for electrical study. They showed marked denervation of the right thenar and hypothenar muscles. In the male patient, the F-response was considerably delayed on both sides but it was normal in both female patients. SNAP amplitudes were absent or abnormally low on the fifth digit in the affected limb in all three cases as shown in Table 4. Compression of the lower trunk of the plexus was confirmed at surgery in the first two patients; the third patient refused surgery.

Nine patients were examined who had the typical history and findings of neuralgic amyotrophy (Parsonage and Turner, 1948). All had acute onset with pain followed by muscular weakness and wasting. There was no evidence of any compressive lesion and recovery eventually took place in all cases.

When this condition, as is most frequent, affects muscles usually supplied by C5, diminution of digital SNAP amplitude would not be expected. Six of the cases had involvement of other roots and of these, case 6 had abnormal SNAPs and case 4 had a probably abnormal result on one digit (Table 5).

\section{Discussion}

For subjects under 50 years of age, the absolute amplitudes of digital sensory responses can be made useful laboratory measurements if 5\% and $10 \%$ lower limits are calculated. In older people and in patients suspected of having selective lesions of $\mathrm{C} 6, \mathrm{C} 7$ or $\mathrm{C} 8$ nerve roots, calculation of ratios of SNAP amplitudes for the digits can give added information. Variability

Table 4: F Wave Latency and SNAP Amplitude in Patients with Thoracic Outlet Syndrome

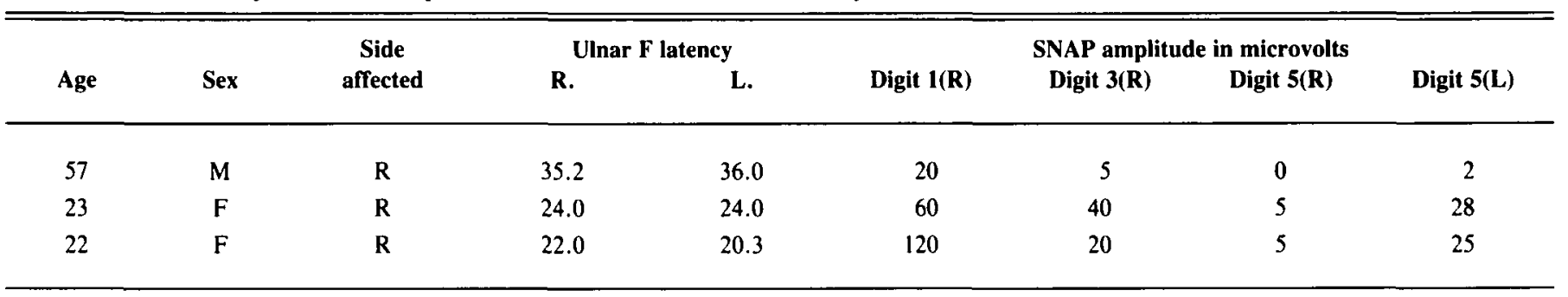

Table 5: SNAP Amplitude in Patients with Neuralgic Amyotrophy involving C6, C7, or C8 Roots

\begin{tabular}{|c|c|c|c|c|c|c|c|c|c|}
\hline Case No. & Age & Sex & Side & $\begin{array}{c}\text { Motor roots } \\
\text { affected }\end{array}$ & $\begin{array}{l}\text { Digits with } \\
\text { sensory loss }\end{array}$ & 1 & 2 & 3 & 5 \\
\hline 4 & 18 & $\mathbf{M}$ & $\mathbf{R}$ & $5,6,7,8$ & 4,5 & $8(17)$ & $7(10)$ & $8(8)$ & $8(8)$ \\
\hline 5 & 34 & $\mathrm{~F}$ & $\mathbf{L}$ & 7 & 3 & 15 & 12 & 14 & 12 \\
\hline 8 & 45 & $\mathbf{M}$ & $\mathbf{L}$ & 8 & - & 15 & 15 & 17 & 8 \\
\hline 9 & 58 & $\mathbf{M}$ & $\mathbf{R}$ & 8,1 & 4,5 & 10 & 8 & 10 & 5 \\
\hline
\end{tabular}

Figures in brackets indicate amplitudes on unaffected hand. 
and overlap of the dermatomes must be borne in mind, as described by Inouye and Buchthal (1977) in man, and by Dykes and Terzis (1981) in experimental animals.

The ratio of the SNAP amplitude from digit five to the other digits is the most variable. This uncertainty probably results because of the variable depth of median and ulnar nerves at the wrist; the median nerve is at a depth of 3 to $7 \mathrm{~mm}$ depending on the presence or absence of palmaris longus; the ulnar nerve, 6 to $8 \mathrm{~mm}$ at a point $2 \mathrm{~cm}$ proximal to the main wrist crease according to Stranc (personal communication). In older subjects, also, subclinical ulnar neuropathy is more difficult to exclude than median nerve lesions. This variability can be overcome to some extent by antidromic recording or by using near-nerve or intraneural needle electrodes. In the former method, the conducted motor response may obscure the sensory amplitude and in the latter, the distance of the electrode from the active nerve fibres is critical. The amplitude of the SNAP from digit five is particularly important in the diagnosis of thoracic outlet syndromes (Gilliatt et al., 1978), while normal SNAPs can help to confirm the diagnosis of an intraspinal root lesion.

Neuralgic amyotrophy or brachial plexus neuropathy is a condition of unknown cause and pathology but characteristic natural history. While the distribution of clinical motor and sensory findings sometimes indicates a peripheral nerve lesion (Weikers and Mattson, 1969), in other cases, such as cases 4, 5 , $7,8,9$ in this series, the lesion could be within the spinal cord or could involve motor roots only. Taken in conjunction with other investigational methods such as EMG of paraspinal muscles, F-response latency and sensory evoked potentials from the scalp, the anatomical sites of the lesions in such cases may become better defined.

\section{REFERENCES}

Benecke, R., Conrad, B. (1980). The distal sensory nerve action potential as a diagnostic tool for the differentiation of lesions in dorsal roots and peripheral nerves. J. Neurol. 223, 231-239.

Bonney, G., Gilliatt, R.W., (1958) Sensory nerve conduction after traction lesion of the brachial plexus. Proc. R. Soc. Med. 57. 365-367.

Cruz-Martinez. A., Barrio, M.. Perez Conde, M.D., Gutierrez. A.M. (1978a). Electrophysiological aspects of sensory conduction velocity in adults. - part (1) J. Neurol. Neurosurg. Psychiatry 41, 1092-1096.

Cruz-Martinez. A.. Barrio. M.. Perez Conde. M.D. . Ferrer. M.T. (1978b). Electrophysiological aspects of sensory conduction velocity in adults. - part (2) J. Neurol. Neurosurg. Psychiatry 41, 1097-1101.

Dykes, R.W.. Terzis. J.K. (1981). Spinal nerve distributions in the upper limb: the organization of the dermatome and afferent myotome. Philos. Trans. R. Soc. Lond. (Biol) 293, 509-554.

Gilliatt. R.W.. Willison. R.G.. Dietz. V.. Williams. I.R. (1978). Peripheral nerve conduction in patients with a cervical rib and band. Ann. Neurol. 4, 124-129.

Inouye, Y., Buchthal, F. (1977). Segmental sensory innervation determined by potentials recorded from cervical spinal nerves. Brain 100, 731-748.

Parsonage, M.J., Turner, J.W.A. (1948). Neuralgic Amyotrophy (paralytic brachial neuritis). Lancet i 973-978.

Weikers, N., Mattson, R.H. (1969). Acute paralytic brachial neuritis. Neurology 19, 1153-1158. 